Objective Occupational stress (OS) has been associated with musculoskeletal disorders (MSKD) and related sickness absences, but the prevalence of MSKD deeply varies across countries and cultural/social variables and could influence their relationship with OS.

As part of the CUPID international study, we compared OS and MSKD in two groups of nursing personnel from Italian andBrazilianUniversityhospitals, countries characterised by different social background and economic environment.

Methods The CUPID Questionnaire and Effort Reward Imbalance Questionnaire (ERI) were administered to all subjects $($ Brazil $=150$, Italy $=311)$ to collect MSKD and related disability/absences, and the perceived OS. Data analysis considered the Wilcoxon's and Chi-square tests to compare answers across the countries, and multivariate logistic regression models to investigate the association between OS and MSKD.

Results The two population resulted comparables distribution of gender (female $=84 \%$ ). Italians reported more frequently to have been exposed to high physical workload in performing their daily job tasks.

In term of OS, Brazilian nurses reported a sensibly lower perceived "effort" and a higher "reward" (median ERI $=0.52$ vs. $0.63, p=0.001)$. In contrast, the prevalence of MSKD was comparable across countries (back and shoulder pain), but the frequency of MSKD-related absences in the last year (one week or more) was sensibly lower in Brazil (5\% vs. 12\%). Even if stress level were different, OS was associated to increased MSKD in both countries (Adj OR for an IQR ERI increase = 1.60 inItaly and OR $=4.14$ in Brazil, $\mathrm{p}<0.05$ for both).

Conclusions Reports of OS resulted very different in two groups, but its relationship with MSKD was present in both countries. The observed difference in MSKD-related absences prevalence had no significance.

\section{UPPER EXTREMITY MUSCULOSKELETAL PAIN IN LEBANESE BAKERY WORKERS}

R Habib. American University of Beirut, Beirut, Lebanon

\subsection{6/oemed-2013-101717.89}

Background Musculoskeletal (MS) pain in the upper extremities is a major cause of morbidity among workers in many occupations. Research links upper extremity pain of the shoulder, neck, wrists, and elbow with physical exertion in the workplace and psychosocial influences like workplace organisation. Lebanon's bakery industry is an important occupational environment to explore MS pain as it features cramped spaces, highly pressured work tasks, and frequent engagement of the upper extremities. Studies assessing musculoskeletal pain among workers are rare in Lebanon, as are studies of bakery workers from developing countries. This study assesses the magnitude of upper extremity musculoskeletal pain among Lebanese bakery workers and determines associations with physical and psychosocial variables.

Methods Surveys were conducted among 504 randomly selected bakeries across Lebanon between April and November of 2010. Samples were proportionate to the number of bakeries in each district of the country. Surveys were administered through faceto-face interviews at the workplace with the consent of employers and workers. The survey included items on musculoskeletal pain, general health, workplace activities and organisation, and socio-demographics. Descriptive and logistic regression analyses were completed using SPSS 20.0.
Results Almost 23\% of workers reported upper extremity pain. Workers reporting poor self-rated health or chronic illness were twice as likely to report painful symptoms, while workers holding a second job were also twice as likely to have MS pain. Workers engaging in tasks with their hands above their shoulders (OR: 2.58; CI: 1.45-4.58) or repeated wrist movements (OR: 2.68; CI: $1.07-6.70)$ were more likely to report MS pain.

Conclusions Physical exertions were correlated with upper extremity MS pain. These results indicate a need to focus future interventions on improving workplace ergonomic conditions and implement workplace safety training in Lebanese bakeries.

\section{WORK-RELATED MUSCULOSKELETAL DISORDERS AMONG WHITE-COLLAR WOMEN EMPLOYEES}

${ }^{1}$ H G Gül, ${ }^{2}$ Issever, 'Babaoglu, ${ }^{2}$ Hapçioglu. 'Istanbul, Turkey; ${ }^{2}$ Istanbul University, Istanbul, Turkey

\subsection{6/oemed-2013-101717.90}

Objectives Work-related musculoskeletal disorders (WMSDs) are one of major occupational health problem in developed and developing countries. WMSDs can affect all workers, but literature reviews indicate that women in general report more symptoms. We aimed in this study to evaluate the prevalence of work-related musculoskeletal disorders and possible risk factors among white-collar women workers in Istanbul, Turkey.

Methods The study design was self-reported questionnaire-based cross-sectional study. We collected personal and occupational information and musculoskeletal complaints of women who work in the service sector. We used modified version of a general standardised questionnaire including a picture of the body sites was used for analyses of perceived symptoms of MSDs. For different parts of the body, participants were asked to indicate whether they have had regular or long-lasting complaints. All data was coded for each of the parameters. A p $<0.05$ was considered statistically significant.

Results Questionnaires of 550 participants were completed and returned back for analysis. Five hundred seven (\%92.2) of female had an university graduate and more. In this study, the age range was between 23 and 60 years. Mean age was $34.77 \pm$ 5.71. MSD was increased with age and $(\mathrm{r}=0.127, \mathrm{p}=0.003)$. Twelve-month prevalence was $89.3 \%$ the most prevalent site affected was that of neck $(74.9 \%)$ followed by back $(74.2 \%)$ and waist $(65.8 \%)$ the least frequent disorder was that of elbows $(0.7 \%)$.

Conclusions The study confirms that white-collar women workers are at higher risk of musculoskeletal disorders. Our findings are similar to the results of the studies on this subject in developed countries. The associations of musculoskeletal disorders with gender and occupational risk factors should be considered especially. Prevention strategies of possible work place risk factors for women can reduce the prevalence of MSDs. It would be helpful to provide continuing education about ergonomic risks in the workplaces.

\section{ASSESSMENT OF TRAPEZIUS MUSCLE PARAMETERS AMONG SITTING AND STANDING WORKERS}

${ }^{1} \mathrm{O}$ K Oha, ${ }^{2}$ Pille, ${ }^{1}$ Merisalu, ${ }^{1}$ Pääsuke. ${ }^{1}$ University of Tartu, Viljandi, Estonia; ${ }^{2}$ Tallinn University of Technology, Tallinn, Estonia

10.1136/oemed-2013-101717.91 